\title{
A emergência da politização da intimidade na experiência de mulheres usuárias de drogas
}

\author{
Marco Aurélio Máximo Prado \\ Universidade Federal de Minas Gerais \\ Isabela Saraiva de Queiroz \\ Pontificia Universidade Católica de Minas
}

\begin{abstract}
Resumo
Tendo como referencial teórico o campo intelectual feminista, este artigo discute a fundamentação moral e sexista do modelo de tratamento proposto pelo serviço de atenção a usuários de álcool e outras drogas conhecido como comunidade terapêutica. A partir do acompanhamento da experiência de um grupo de mulheres em tratamento em serviço aberto (CAPS-AD), apresenta-se a possibilidade de constituição de um espaço de politização da intimidade de mulheres usuárias de drogas. Ao final, discute-se que, para além do tratamento do uso abusivo de drogas, o trabalho no grupo de mulheres potencializou o questionamento da sua condição de gênero, por meio da interpelação coletiva sobre as relações de subordinação e opressão às quais estão submetidas e do reconhecimento dos lugares de fragilidade e insuficiência historicamente a elas atribuídos.
\end{abstract}

Palavras-chave: mulheres; uso abusivo de drogas; feminismo; politização da intimidade.

\begin{abstract}
The politicization of intimacy in the experience of women who use drugs. Based on conceptual frameworks from the feminist intellectual field, this article discusses the moral and sexist foundations of the treatment model of alcohol and drug abuse known as the therapeutic community. From the analysis of the experience of a group of women in treatment at an open public service (CAPS-AD), we suggest the creation of a space for the politicization of the intimacy of the women who use drugs. Finally, we show that, beyond the drug abuse treatment, the work with these women increased the questioning of their gender condition, through the group discussion about the relations of subordination and oppression to which they are submitted and the increased awareness of the situation of vulnerability and insufficiency historically assigned to them.
\end{abstract}

Keywords: women; drug abuse; therapeutic community; feminism; politicization of intimacy.

\section{Introdução}

Uma das esferas que convoca as políticas públicas de saúde a repensar seus modelos de atenção com urgência é o campo das políticas de álcool e drogas, particularmente no que tange às respostas dadas aos desafios colocados à sociedade brasileira para lidar com os problemas decorrentes do uso de substâncias. Ao mesmo tempo em que assistimos a um aumento marcante do uso de álcool e outras drogas no Brasil (Carlini, Galduróz, Noto, \& Nappo, 2002; Galduróz, Noto, \& Carlini, 1997), vemos que, nesse campo, conforme Carlini (1999), "continamos tendo somente um certo vigor político (pelo menos no campo da retórica) quando se trata de discutir políticas de tratamento de dependência" (p. 10). Nesse sentido, no contexto brasileiro, o serviço conhecido como comunidade terapêutica vem desenvolvendo ações de tratamento da dependência em escalas cada vez mais crescentes, ocupando o lugar deixado vago pelas políticas públicas de álcool e drogas.

Para compreendermos o surgimento das comunidades terapêuticas, devemos voltar um pouco na história da psiquiatria, segmento que inspira o campo da saúde mental em suas diversas áreas de ação. No Brasil, este campo sofreu grande influência da reforma sanitária psiquiátrica proposta por Basaglia na Itália no final dos anos 70 (Berlinck, Magtaz, \& Teixeira, 2008). As várias denúncias sobre a política nacional de saúde mental, inspiradas pelas ideias da reforma sanitária, promoveram a proposição de serviços pautados na desistitucionalização e humanização do tratamento, com vistas à reinserção social dos pacientes psiquiátricos.

Todo este movimento de reforma trouxe para a saúde mental uma ampliação dos serviços, proporcionando, assim, atenção mais diversificada às especificidades dos seus usuários. 
Sabe-se, contudo, que, ao contrário das demais parcelas de cidadãos antes institucionalizados, as pessoas com problemas decorrentes do uso abusivo de drogas permaneceram sob o jugo de modelos moralizantes e manicomiais de tratamento (Brasil, 2005): "produziu-se historicamente uma importante lacuna na política pública de saúde, deixando-se a questão das drogas para as instituições da justiça, segurança pública, pedagogia, benemerência, associações religiosas" (p. 40).

Somente em 2002, com a criação dos CAPS-AD (Centros de Atenção Psicossocial - Álcool e Drogas), serviço de referência na rede de saúde mental para implantação das políticas de promoção da saúde, prevenção e tratamento de sujeitos com abuso/dependência de álcool e drogas, os usuários de drogas começaram a receber tratamento mais direcionado, em serviços ambulatoriais de atenção-dia. A implantação dos CAPS-AD poderia ter significado um modelo de atenção diferenciado (Mata, 2008), apesar disso, essas iniciativas não parecem ter absorvido toda a demanda de atenção, nem ter produzido impacto direto sobre as ações da sociedade civil neste campo, uma vez que os dados sinalizam nesse mesmo período um crescimento no número de comunidades terapêuticas. (Sabino \& Cazenave, 2005).

As instituições conhecidas como comunidades terapêuticas não são recentes. O termo Comunidade Terapêutica foi consagrado por Maxwell Jones, na Inglaterra, em 1959, para caracterizar um movimento de reforma do hospital psiquiátrico, marcado pela adoção de medidas administrativas democráticas, participativas e coletivas. O serviço hoje popularizado como comunidade terapêutica para tratamento da dependência química retoma, então, os pressupostos das comunidades terapêuticas oriundas da psiquiatria reformada, sendo acrescido, contudo, de alguns princípios presentes em outras estratégias de abordagem à dependência química, em especial ao alcoolismo, consagradas nos conhecidos grupos de alcóolicos anônimos.

Os grupos de AA, que tiveram origem nos Estados Unidos, em 1935, têm como princípios organizadores da sua prática a autoajuda e a ajuda-mútua, sendo a crença dos indivíduos em si mesmos, em um "poder superior" e, principalmente, no grupo, seus substratos fundamentais. Reproduzindo estas primeiras orientações, grande parte das comunidades terapêuticas atuais estabelecem o regime de vida comunitária como elemento fundamental do tratamento, que segue um programa fundamentado na disciplina, na espiritualidade e no trabalho como recursos terapêuticos. (De Leon, 2003)

O panorama traçado acima nos possibilita discernir os contornos de um modelo de atenção à saúde fundamentado no discurso jurídico-moral, que estabelece modos de vida ditos corretos e dignos de manutenção e reprodução hegemônica, pautados numa visão dicotômica da realidade que define campos de normalidade e anormalidade, notadamente marcados por desigualdades e mantidos pela força do poder disciplinar. Esse modelo de atenção estabelece como critério de saúde e, por consequência, de cura da dependência química, a abstinência de quaisquer substâncias psicoativas, associada a uma mudança comportamental com vistas à adoção de um "estilo de vida saudável". Nesse modelo de discurso, qualquer retomada do uso de substâncias psicoativas é vista como um fracasso, promovendo um retorno ao tratamento que, não raro, leva a um ciclo de reinternações. Não são discutidas estratégias de redução de danos, nem considerados válidos arranjos pessoais construídos pelo próprio sujeito para lidar com seu uso (algumas vezes abusivo) de drogas.

Esse cenário denuncia a comunidade terapêutica como um dispositivo de saúde anacrônico do ponto de vista das conquistas apresentadas pela reforma psiquiátrica. Supomos, contudo, que as representações positivas em torno da ideia de reclusão do dependente químico e da manutenção da lógica manicomial interferem decisivamente na organização das práticas sanitárias deste campo. Tal afirmação ganha força quando nos deparamos com a organização das políticas públicas sobre drogas no Brasil e o modo como ela historicamente se constituiu pela lógica da segurança pública, estando só muito recentemente sendo discutida no campo da saúde pública. De todo modo, cabe ressaltar que, mesmo no campo da saúde, a política de atenção ao usuário de drogas é orientada para o tratamento da dependência, ainda pensado sob a égide da abstinência. Intervenções baseadas na redução de danos, embora representem a política oficial do Ministério da Saúde para o tratamento do usuário de álcool e drogas, ainda são pouco conhecidas e aceitas, o que reforça a denúncia da supremacia da lógica manicomial no campo da atenção ao usuário de álcool e outras drogas.

\section{Redução de danos e política}

Segundo Marlatt (1999), antes de se tornar um conceito e uma estratégia científica, a redução de danos deu-se enquanto movimento político. Por volta dos anos 70, na Holanda, vinha sendo estruturada uma política nacional tolerante às drogas. Especificamente no ano de 1972, antes mesmo da emergência da epidemia de AIDS (Síndrome da Imunodeficiência Adquirida), houve a publicação de um documento pelo Comitê de Narcóticos, no qual ficou concluído que "as premissas básicas de uma política de drogas deveriam ser congruentes com a extensão dos riscos envolvidos no uso das mesmas" (p. 31), o que convergia para a aplicação de intervenções via redução de danos. Tal política, segundo Reale (1997), refletia o princípio implícito de que o que deveria estar no centro das ações neste campo não era mais a erradicação do uso da droga ilícita, mas a minimização do seu dano.

Concomitantemente a este processo de desenvolvimento e implementação de uma política holandesa tolerante às drogas, no início dos anos 80 , neste mesmo país, um grupo de usuários preocupados com o aumento do número de casos de hepatite e com a possibilidade de limitação no acesso a agulhas e seringas, organizou-se no sentido de obter, através da troca, equipamentos estéreis. A partir de então, através da auto-organização destes usuários numa espécie de "sindicato para usuários de drogas pesadas", chamado Junkiebond (Liga de Dependentes) (Marlatt, 1999), houve um impulso para a geração de novas organizações de usuários de drogas locais, o que culminou na viabilização de propostas de redução de danos em conjunto com o estado holandês. O ponto de partida da Junkiebond era zelar pelos interesses dos usuários de drogas, sendo que o mais importante era combater a sua deterioração. A participação dos dependentes associados à Junkiebond levou à implantação do primeiro 
programa de troca de seringas em Amsterdã, em 1984.

Enquanto isso, em Liverpool, Inglaterra, as estratégias de redução de danos como prática de saúde pública instituída encontravam sustentação. Segundo Marlatt (1999), a partir de 1985, os dependentes passaram a dispor de uma grande variedade de serviços, incluindo: troca de seringas e educação em sua comunidade, prescrição de drogas como heroína e cocaína; serviços de aconselhamento, emprego e moradia; tratamento para a dependência, incluindo internação para desintoxicação. É relevante assinalar que somente cerca de $10 \%$ dos usuários interessavam-se por um tratamento cuja meta fosse livrar-se do uso de drogas (Marlatt, 1999).

Segundo Reale (1997), o reconhecimento das intervenções sustentadas na redução de danos como básicas e diretivas deuse, no contexto inglês, por intermédio de fatores intimamente vinculados à emergência da epidemia de AIDS. Para este autor, percebe-se claramente uma diferença ideológica entre os dois movimentos pioneiros em redução de danos, ou seja, o modelo de Liverpool, Inglaterra, o qual se estrutura a partir de justificativas que legitimam a necessidade de intervenções alternativas e eficazes no âmbito da saúde pública, e o modelo holandês, que se funda numa articulação social entre organizações governamentais e um grupo específico da sociedade civil organizada, o que dá a este um cunho muito mais político e ao de Liverpool, um cunho mais científico.

O marco deflagrador do movimento de redução de danos em âmbito internacional foi, em 1990, a I Conferência Internacional de Redução de Danos, ocorrida em Liverpool, onde a principal preocupação foi a de promover a divulgação da proposta e a articulação de apoios e parcerias. A partir desta primeira conferência internacional decidiu-se por encontrar meios cada vez mais efetivos para a pulverização da redução de danos no mundo buscando seu paulatino reconhecimento. Para tanto, a partir da III Conferência, ocorrida em 1992, ganha importância a necessidade de obter-se reconhecimento científico das práticas e saberes que compõem a proposta e, assim, a busca de enquadramento científico das propostas de redução de danos passa a ser o objetivo central do movimento (Reale, 1997). Pode-se dizer que o seu principal desdobramento é a presença de programas de redução de danos na maioria dos países considerados desenvolvidos.

A primeira iniciativa de criação de um PTS no Brasil se deu em Santos, em 1989, pela Secretaria Municipal de Saúde. Esta iniciativa correspondia à intenção de implantação de uma série de estratégias de redução de danos voltadas aos usuários de drogas injetáveis na cidade de Santos uma vez que, nesta época, os índices de infecção pelo HIV entre os Usuários de Drogas Injetáveis (UDI) eram os maiores registrados no país, tendo atingido 59\% em 1992 e 65\% em 1993 (Reale, 1997). Contudo, restrições legais foram impostas pelas autoridades judiciais locais, o que fez com que o programa deixasse de fazer troca de seringas, mantendo, não obstante, as demais ações de prevenção do HIV, especialmente entre usuários de drogas injetáveis (ao invés de troca de seringas, passou a ser feita a lavagem de seringas com hipoclorito de sódio).

O primeiro PTS, oficialmente financiado pelo Ministério da Saúde, foi o Projeto de redução de danos entre usuários de drogas injetáveis em Salvador, em abril de 1995. Este programa, diferentemente do de Santos, não teve problemas com a justiça local, graças a um conjunto de articulações que são específicas de cada realidade geo-política-social. No caso de Salvador, acredita-se que a boa aceitação das autoridades locais deuse, principalmente, pelo fato de o programa estar associado a uma instituição universitária de tratamento de dependência e prevenção de drogas, sendo um dos centros de referência nacional no assunto (CETAD/UFBA). Este projeto mostrou à imprensa e à sociedade que o trabalho com redução de danos pode trazer resultados positivos, dando credibilidade para a implantação de programas em outros estados no Brasil (Reale, 1997). Atualmente, a redução de danos constitui a abordagem preventiva oficial pela qual a epidemia de AIDS vem sendo enfrentada no Brasil (Brasil, 1996).

Importa lembrar que a redução de danos não é apenas uma alternativa à abstinência no tratamento da dependência química, antes, trata do manejo seguro de uma ampla gama de comportamentos de alto risco e dos danos associados a eles. O importante na redução de danos não é se determinado comportamento é bom ou ruim, certo ou errado, mas se é seguro ou inseguro. (Marlatt, 1999). Em síntese, adotar condutas de redução de danos pressupõe que suportemos a ideia de vivermos fora do campo dos ideais, encontrando formas alternativas de diminuir os prejuízos que podem ser gerados a partir de um determinado comportamento.

Em “A invenção do presente”, Melucci (2001) diz que "os movimentos são um sinal [...] são a mensagem daquilo que está nascendo" (p. 21) Dessa forma, eles vêm indicar uma transformação na lógica e nos processos que guiam as sociedades complexas, anunciando aquilo que está se formando "sem que ainda disso esteja clara a direção e lúcida a consciência” (p. 21). Para ele, "os movimentos contemporâneos anunciam a mudança possível, não para um futuro distante, mas para o presente da nossa vida" (p. 21). Podemos entender a partir disso o lugar ocupado pelo movimento dos usuários de drogas na Holanda, qual seja, o de anunciador de uma nova forma de pensar o uso e o abuso de drogas, inaugurando uma nova abordagem, alternativa aos modelos tradicionais e fundamentada nas ideias de controle do uso e redução dos danos associados ao abuso de drogas.

É justamente esta elaboração cotidiana de significados alternativos da conduta individual e coletiva que caracteriza a atividade principal das redes de movimentos contemporâneos. Segundo Melucci (1999), estes movimentos têm como função principal revelar o que o sistema não diz de si mesmo. "Os movimentos declaram que a estrutura que o poder propõe como solução dos problemas, não só não é a única solução possível, mas esconde interesses específicos e um núcleo de poder arbitrário e de opressão" (p. 64, tradução nossa). O anúncio que a política de redução de danos faz é o da possibilidade de haver outras estratégias de abordagem ao uso e abuso de drogas que não aquela fundamentada na repressão, exclusão e associação imediata a problemas médicos.

Se pensarmos, então, que tanto a maneira de ver quanto de tratar o usuário de drogas estão diretamente relacionadas ao lugar que este ocupa na malha social e, considerando que o campo relativo à temática de álcool e drogas é um campo de disputas, 
envolvendo atores bastante hierarquizados, fica evidenciado o quanto várias hierarquias, como as de classe e gênero, podem estar presentes na composição dos saberes e práticas que definem a política de álcool e drogas no Brasil.

Para além das críticas à ausência de uma política específica de atenção ao usuário de álcool e outras drogas e à emergência das comunidades terapêuticas como dispositivo privilegiado de tratamento da dependência, ao longo de nossa experiência profissional nestes serviços tornaram-se visíveis as diferenças no modo como o tratamento direcionado a homens e mulheres é concebido. Para os homens o tratamento é visto como um meio de aquisição ou retomada de habilidades pessoais e técnicas para o retorno à vida social, especialmente vinculada ao trabalho, com temas como seguro-desemprego e previdência, por exemplo, sendo uma preocupação comum entre eles. No caso das mulheres, o foco da "reabilitação" encontra-se na retomada dos vínculos familiares e na adequação social, inspirada por um viés conservador e patriarcal. Além disso, às mulheres cabe o título não só de dependentes, mas também de desarrazoadas, indóceis, presas de ditames naturais e incomunicáveis. Soma-se a isso a noção de que são de "difícil tratamento", aderindo fragilmente à proposta de vida comunitária, dentre outras designações que parecem revelar um preconceito de gênero, mantido às custas da naturalização de condutas tidas como inerentes à mulher.

Importa lembrar ainda que a fundamentação religiosa da imensa maioria das comunidades terapêuticas reforça o lugar das mulheres como representantes do privado, do cuidado e da maternidade, sendo o uso abusivo de drogas, que rompe com esses lugares idealizados, visto como duplamente condenável. Soma-se a isso o fato das mulheres historicamente terem sido colocadas como sujeitos dependentes - dos homens ou dos programas do Estado, que também é uma entidade masculina (Fraser, 2009) -, sendo os homens vistos como portadores de direitos e as mulheres como aquelas que "necessitam" de benefícios, o que faz com que os programas direcionados às mulheres tenham, em sua maioria, um caráter essencialmente assistencialista.

Marca visível destas concepções encontram-se nos discursos de profissionais destes serviços e compuseram a justificativa para o recente fechamento de uma comunidade terapêutica para mulheres no município de Belo Horizonte. Somou-se a isso a inexistência de um quadro de profissionais qualificados para o trabalho em comunidades terapêuticas para mulheres, já que dentre os critérios exigidos para o cargo de monitoria de comunidade terapêutica está que o monitor já tenha passado pelo tratamento de internação e seja do mesmo sexo dos usuários. Além disso, as práticas sociais tradicionalmente atribuídas às mulheres não condizem com as exigências de um trabalho em comunidade terapêutica, uma vez que este exige a ruptura com a vida em família para a adoção de um modelo de vida comunitária.

Tais concepções sobre a diferença entre homens e mulheres não são isoladas, nem estão presentes de forma particular nas comunidades terapêuticas. Refletem o modo como organizamos saberes e práticas sociais relativas ao sistema de classificação de gênero, e denunciam a nossa inscrição numa sociedade sexista e androcêntrica.

\section{Mulheres, uso de drogas e corporalidade}

De acordo com Grosz (2000), o pensamento misógino "frequentemente encontrou uma autojustificativa conveniente para a posição social secundária das mulheres ao contê-las no interior de corpos que são representados, até construídos, como frágeis, imperfeitos, desregrados, não confiáveis, sujeitos a várias intrusões que estão fora do controle consciente" (p. 67). Desse modo, historicamente as mulheres foram, pela via do patriarcado, muito mais vinculadas aos corpos do que os homens, o que fez com que seus papéis sociais e econômicos ficassem restritos a lógicas que se apoiam no essencialismo e no biologicismo. Daí a suposição de que "dadas certas transformações biológicas, fisiológicas e endocrinológicas específicas, as mulheres são, de algum modo, mais biológicas, mais corporais e mais naturais do que os homens" (p. 68).

É assim que vemos determinadas práticas sociais destinadas à promoção da saúde do corpo serem atribuídas de modo diferenciado a homens e mulheres, fazendo com que a exposição ou proteção dos indivíduos a determinadas doenças e/ou problemas de saúde aconteça também de forma diferenciada. Nesse sentido, segundo Victora e Knauth (2004), ao mesmo tempo em que práticas consideradas perigosas e violentas (como os esportes radicais, o uso de drogas e a violência) são vinculadas em diversas culturas à masculinidade, em determinados segmentos sociais vincula-se feminilidade e beleza, o que estimula a adoção de práticas também específicas, como dietas radicais, cirurgia plástica e lipoaspiração. Ambas as vinculações geram consequências particulares sobre a saúde de homens e mulheres.

Importa lembrar ainda que o próprio conhecimento médico se construiu, em grande medida, a partir de um pressuposto de fragilidade do corpo da mulher (Victora \& Knauth, 2004), o que estabelece práticas corporais específicas às mulheres, quase sempre convencionadas a espaços sociais regidos pela proteção e pelo controle. Essas prescrições feitas ao corpo da mulher fizeram com que se produzisse um ocultamento de determinadas práticas sociais não atribuídas diretamente às mulheres.

Nesse sentido, segundo o UNODC1, em 2005 foi registrado um aumento global de 15 milhões de pessoas, na faixa etária de 15 a 64 anos, envolvidas com o consumo de drogas, e neste contingente foi identificado o aumento do número de mulheres em relação ao de homens para alguns tipos de drogas, especialmente as ilícitas. (Oliveira, Paiva, \& Valente, 2006). Para as autoras, uma explicação possível para o aumento do número de mulheres usuárias de drogas pode estar no fato delas terem sido sub-representadas em estudos sobre esta temática, já que o uso abusivo de drogas historicamente esteve relacionado aos homens.

Para Oliveira et al. (2006), o uso abusivo de drogas por mulheres está associado a necessidades e situações específicas, quase nunca consideradas nos serviços de atenção a usuários de drogas, tendo em vista a tendência à homogeneização das práticas neste campo. De um modo geral, nas mulheres o uso de drogas está associado à gravidez, responsabilidades nos cuidados com crianças, trabalho com sexo, traumas decorrentes de abuso físico e sexual experienciados na infância e/ou adolescência e, ainda, a níveis mais altos de problemas de saúde mental e crônica em 
relação aos homens.

Pesquisas do Programa de Atenção à Mulher Dependente Química (PROMUD), do Instituto de Psiquiatria do Hospital das Clínicas da Faculdade de Medicina da Universidade de São Paulo (Ipq-HC-FMUSP) (Hochgraf, 2001), ampliam os dados apresentados por Oliveira et al.: enquanto mulheres relatam mais problemas intrapsíquicos associados ao uso abusivo de drogas, como depressão, baixa autoconfiança, irritabilidade e dificuldade em prever os próprios sentimentos, os homens referem-se frequentemente a problemas externos, como dificuldades profissionais, financeiras e criminais. Em outra pesquisa, Hochgraf, Zilberman e Brasiliano (1999) também identificaram diferenças nas razões que levam mulheres e homens a iniciar o uso de drogas. Novamente, nas mulheres, no caso específico da cocaína, o uso de drogas é associado à depressão, sentimentos de isolamento social, pressões profissionais e familiares e problemas de saúde. Nos homens, por outro lado, o uso da cocaína não é associado a um fator desencadeante especial, sendo justificado pelos efeitos da intoxicação propriamente dita. Por fim, dados da pesquisa de Henderson, Boyd e Mieczkowski (1994) apontam que as mulheres, em geral, iniciam o uso de drogas levadas pelo companheiro, enquanto os homens o fazem com os amigos.

$\mathrm{O}$ argumento sustentado aqui é de que todas as situações descritas acima como tipicamente associadas ao abuso de drogas em mulheres reproduzem desigualdades de gênero sustentadas por prescrições do patriarcado que estabelecem às mulheres uma condição de insuficiência e submetimento. Tal condição de fragilidade e consequente necessidade de proteção justificariam estratégias de controle e vigilância sobre as mulheres, mantidas ainda por uma lógica de cuidado diferenciado decorrente de sua função reprodutora. Daí todo um aparato governamental de manejo e submetimento pautado por ações de normatização da saúde que, sob o discurso de uma atenção especializada, serve à manutenção das hierarquias de gênero e dos lugares inferiorizados tradicionalmente atribuídos às mulheres.

Para Grosz (2000), "como instrumento ou ferramenta, ele (o corpo das mulheres) pede disciplina e treinamento cuidadosos e, como objeto passivo, requer conquista e ocupação" (p. 59). Nesse sentido, Grosz (2000) ressalta a importância das lutas políticas feministas que utilizam o slogan "tire suas leis de meu corpo", uma vez que denunciam esta visão tipicamente passiva e improdutiva do corpo da mulher, "objeto sobre o qual podem existir disputas entre seus 'habitantes' e outros/exploradores" (p. 59). É esta inércia do corpo da mulher que justificaria a possibilidade de se atuar sobre ele, coagi-lo ou constrangêlo através de forças externas. Grosz (2000) pondera que não se trata de desconsiderar situações reais de violação, mas de admitir "contextos nos quais os corpos das mulheres possam ser reconhecidos como ativos, viáveis e autônomos" (p. 59), de modo que práticas de submetimento e controle não possam mais ser racionalizadas ou reproduzidas conscientemente.

\section{Demarcando o campo intelectual feminista como organizador da discussão}

O campo intelectual do qual emergem os contornos da discussão aqui proposta se define por duas inscrições indissociáveis: a primeira, que institui o campo de estudos acadêmicos sobre as mulheres e sobre as relações de sexo/ gênero, e a segunda, derivada dos movimentos sociais feministas e de "liberação das mulheres" dos anos setenta. Deste modo, as incursões intelectuais e acadêmicas que buscam a inserção do feminismo como campo intelectual explicitam sua identidade em torno da capacidade de propor um pensamento crítico e inovador na área, caracterizado por tonalidades utópicas, cuja principal aspiração não é introduzir temáticas novas, mas perspectivas de análise e modos de interrogação críticos ao próprio modo dominante de produção de conhecimento, de caráter androcêntrico.

Assumimos aqui, então, junto com Machado (1994), o reconhecimento de um novo quadro de interrogações que estabelece como ponto de partida analítico "a originalidade das formas de reflexão sobre as experiências vividas e da reflexão teórica e política sobre os saberes científicos emergidas em um campo de movimento social" (p. 06). Nesse contexto podemos afirmar que o ponto de vista feminista introduz a questão do olhar da subjetividade dos dominados, de modo que as explicações naturalizantes sobre os processos de dominação dêem lugar à "interrogação sobre a subjetividade dominada frente ao efeito da dominação" (p. 17).

O desenvolvimento do conceito de gênero se justifica pela existência de uma classificação das pessoas entre fêmeas e machos e pelas circunstâncias sociais e psíquicas que rodeiam cada um desses grupos numa sociedade sexista. Izquierdo (1998) sugere que "o fato de ocupar certas posições - independentemente do sexo que se tenha - define relações de subordinação e desigualdade social" (p. 41, tradução nossa).

Tendências mais recentes nos estudos de gênero apontam para a desconstrução das distinções dicotômicas de gênero. Autoras como Judith Butler (2003) propõem que "tudo é gênero", no sentido de que tudo é construído, afirmando nesse sentido que o gênero é corpóreo, já que a materialidade do corpo também está sujeita à construção. Para ela, não há motivo para pensarmos que os gêneros devam permanecer como dois, revelando que "a presunção de um sistema binário de gênero retém implicitamente a crença em uma relação mimética do gênero com o sexo" (p. 08). Ao contrário disso, quando pensamos a posição de gênero como radicalmente independente do sexo, o gênero passa a ser um atributo que flui livremente, com a consequência de que o masculino e o feminino podem dizer respeito a corpos de qualquer sexo, isto é, tanto machos quanto fêmeos. (Izquierdo, 1998; Butler, 2003).

Nesta mesma direção, Mouffe (1993) afirma que, para que possamos compreender adequadamente a variedade de relações sociais, as identidades essenciais devem ser questionadas, particularmente se mantivermos um compromisso político de caráter democrático radical. Do mesmo modo, um mesmo indivíduo, seja homem ou mulher, pode se encontrar situado em diferentes posições de gênero.

Também para Grosz (2000), não há corpo enquanto tal: "existem apenas corpos - masculinos, femininos, negros, pardos, brancos, grandes ou pequenos - e a gradação entre eles" (p. 78). O que importa questionar é o fato de que em algumas culturas, a Ocidental, por exemplo, um determinado corpo - masculino, branco, jovem, saudável - assumir a função de modelo ou ideal 
de corpo "humano" para todos os outros tipos de corpo. Nesse caso, diz a autora, "sua dominação deve ser solapada através da afirmação desafiadora de uma multiplicidade, um campo de diferenças, de outros tipos de corpos e subjetividades." (p. 78).

\section{Identidade: alteridade e diversidade}

O que está posto em questão pelas autoras acima é o próprio conceito de identidade. Deste modo, as próprias categorias homens e mulheres não poderiam mais ser compreendidas em termos estáveis ou permanentes, o que abala a própria essência da teoria feminista que, segundo Butler (2003), "deflagra os interesses e objetivos feministas e constitui o sujeito mesmo em nome de quem a representação política é almejada" (p. 17). Butler (2003) aponta que há, então, tanto o equívoco das ideias "fundacionistas" que sustentam a noção de sujeito, quanto um problema político no fato do feminismo considerar que o termo mulheres (mesmo no plural) denota uma identidade comum.

Tendo em vista esses novos direcionamentos, cabe introduzir aqui o conceito de alteridade como dimensão representativa desse trânsito possível entre diversas posições de gênero. A dimensão de alteridade que queremos apresentar aqui não está, pois, assentada sobre a ideia de uma diferença que se estabelece em termos quantitativos, e sim numa distinção que se dá num processo de relação, que exige sempre dois e não um. A alteridade, segundo Machado (1994), diz respeito então a uma relação que sempre remete à "qualidade distinta e reversível de um a outro e de outro a um" (p. 20), não dizendo respeito a qualquer essência, mas à própria instauração da relação. É assim que podemos dizer que entre dois há identidade e alteridade, de caráter transitório e reversível, postas sempre em historicidade.

$\mathrm{O}$ debate em torno do conceito de identidade nos estudos feministas contemporâneos é complexo e coloca em cena, de uma maneira nova, a questão da universalidade da identidade feminina e da opressão/dominação masculina. Butler (2003) salienta que a multiplicidade das interseções culturais, sociais e políticas que origina o "espectro concreto das mulheres" é rejeitada quando se adota a categoria mulheres a partir de uma dimensão marcada pelas noções de unidade e coerência, ainda que estas unidades absorvam a dimensão relacional.

Importa salientar, por fim, que uma importante limitação do feminismo como campo intelectual advém da sua herança ideológica com marcos sociais muito precisos, emergindo de reflexões propostas por mulheres escolarizadas, de camadas sociais médias e urbanizadas. Deste modo, para Sarti (2004), os estudos feministas contemporâneos admitem que "recursos de ordem material e simbólica não são acessíveis a todas as mulheres, sobretudo na sociedade brasileira" (p. 44). E assim, ainda que o feminismo possa ser reconhecido como um movimento que traz genericamente benefícios à condição social da mulher, a possibilidade de identificação com suas bandeiras não se dá de forma generalizada, o que aponta para a relevância social e política de pensar os limites do feminismo em sua perspectiva universalista. Pode-se dizer, portanto, que as mudanças provocadas pelas proposições feministas convivem frequentemente com posturas tradicionais, especialmente em contextos carregados de discursos depreciativos e moralizantes, como é o campo das dependências químicas.

\section{Mulheres e dependência: uma leitura sob a lógica da opressão sexista}

A discussão teórica realizada nos fornece pontos de partida para o questionamento da proposta metodológica das comunidades terapêuticas direcionadas às mulheres com histórico de uso abusivo de drogas. Como discutido acima, tal proposta, fundamentada em um discurso moral religioso (Acselrad, 2000), reproduz um processo de inferiorização social, promotor de lógicas relacionais opressivas, construídas historicamente numa sociedade sexista que atribui à mulher uma posição de subordinação frente ao homem. Contudo, para que uma relação de opressão possa ser reconhecida como tal, deixando de ser algo justificável por uma suposta organização social necessária, é mister, segundo Prado e Machado (2008) que "os atores sociais subordinados anteriormente reconheçam na inferiorização social uma injustiça historicamente construída, tomando a ordem social como objeto de questionamento, reflexão e interpelação" (p. 69). Os autores completam ainda que, nesse processo, “o exercício da desconstrução de significados cristalizados e rígidos, o enfrentamento político na arena pública e a configuração de uma identidade coletiva como um 'nós' são de elevada importância" (p. 69).

Esta argumentação, somada às contribuições do campo de estudos feminista, sugere que a inscrição da discussão sobre o uso e dependência de drogas no campo da política poderia fazer com que a experiência com drogas deixasse de ser falada exclusivamente pelos especialistas, passando a ser discutida no interior de sua própria produção, o que colaboraria para a ampliação do debate sobre uso de drogas por mulheres do campo meramente moral e pessoal para o campo político.

Pensar políticas de reconhecimento - incorporando o deslocamento da discussão sobre o uso de drogas de um campo que se propõe terapêutico, mas que se faz atravessado por questões morais disfarçadas por um cientificismo sexista, para o registro do campo político - é tarefa desafiadora, seja por lidarmos com um campo inscrito na ilegalidade, seja pela proposição de ser dada voz a um grupo social até então tido como incapaz de elaborar sentidos e significados positivos às suas experiências, caracterizadamente marginais. Pensar estratégias e elaborar reflexões coletivas sobre a subalternidade da condição de "drogada" através da criação e manutenção de espaços de sociabilidade e de identificação poderia, então, indicar uma proposta nova de abordagem à questão do uso abusivo de drogas.

No entanto, como pensar na instauração de uma discussão política, de caráter igualitário, com vistas à formação de compromissos mútuos, eticamente orientados, se tratamos de sujeitos erigidos sobre um fundamento essencialista, que define posições sociais e uma divisão sexual do trabalho que estabelece lugares desiguais para homens e mulheres? O que levantamos como hipótese aqui é que em alguns casos a própria disfuncionalidade presente no uso abusivo ou dependente de drogas diz respeito a um sofrimento derivado do fato de vivermos sob condições sociais sexistas. Trata-se, portanto, de estabelecer o campo intelectual feminista como solo de onde pode emergir uma leitura inovadora sobre a questão do uso abusivo de drogas em mulheres. 
Cabe estabelecer que a novidade inaugurada pelo campo dos estudos feministas na produção acadêmica não se dá pelas temáticas postas em discussão, mas pelos aspectos metodológicos redefinidos pela interrogação permanente em torno da condição de produção e autoria dos saberes. $\mathrm{O}$ feminismo como campo intelectual propõe dessa forma um questionamento das próprias relações de poder no âmbito da produção científica e acadêmica, numa tentativa de compreensão e deslocamento desses poderes constituídos.

Outro princípio característico das metodologias próprias do campo de estudos feministas é o reconhecimento da intimidade como objeto de politização e a investigação sobre as vivências subjetivas. Para tanto, em nosso caso, a pesquisa deve produzir um conhecimento não sobre as mulheres, mas com as mulheres, a partir de sua própria reflexão sobre as experiências vividas com as drogas. É assim que o novo quadro de interrogações estabelecido pelo feminismo estabelece como ponto central da sua investigação o reconhecimento da originalidade das formas de reflexão sobre as experiências vividas que, junto com a reflexão teórica e política sobre os saberes científicos que emergem de um campo de movimento social, compõe um saber que se propõe ao mesmo tempo utópico e crítico.

A possibilidade de emergência de uma experiência de politização da intimidade tem sido experimentada no acompanhamento de um grupo de mulheres usuárias de drogas, em CAPS-AD. Através da constituição do que aqui chamamos de grupo dispositivo (Barros, 2007), trabalha-se com as participantes o questionamento da sua condição de gênero. Ao compartilharem no grupo suas trajetórias de vida e uso de drogas, experiências de violência, humilhação e submetimento emergem tecendo um pano de fundo que parece compor justificativas comuns para o uso abusivo de drogas.

Por um lado, percebe-se em algumas participantes o questionamento das condições sexistas às quais estão submetidas, responsável muitas vezes por episódios de violência de gênero (como é o caso de uma participante que fora mandada para a casa da avó para "aprender a ser uma menina", ainda na infância). Por outro lado, histórias marcadas pela impotência e submetimento também ajudam a compor um cenário de violência sexista, estando nesses casos, contudo, a violência internalizada e sendo justificada pela assimilação do preconceito. Relatos de abandono e da convivência com companheiros agressores são comuns na composição deste segundo grupo de histórias, assim como são comuns relatos de humilhação e desqualificação (como o de uma participante que recebe um dinheiro do companheiro para fazer uma compra de supermercado e é surpreendida ao descobrir, quando chega ao caixa, que o dinheiro era falso, tendo que responder pessoalmente por tentativa de estelionato, já que o companheiro, responsável direto pelo fato ocorrido, nega qualquer envolvimento com o caso).

O compartilhamento de suas histórias no grupo tem permitido às mulheres a coletivização da experiência e a desconstrução de explicações individualizantes para o uso abusivo de drogas. Nesse sentido, para Barros (2007), os grupos dispositivos se constituem como uma via de emergência do político, uma vez que forçam processos de desindividualização, privilegiando a dimensão coletiva da experiência. Deste modo, os grupos dispositivos mostram-se capazes de produzir o que aqui chamamos de práticas de liberdade. É assim, por meio da interpelação coletiva sobre as relações de subordinação e opressão às quais estão submetidas e do reconhecimento dos lugares de fragilidade e insuficiência historicamente a elas atribuídos, que o grupo potencializa nas mulheres o questionamento da sua condição de gênero.

Importa acentuar que, ainda que o grupo dispositivo guarde uma potência virtualmente libertária, esta não é garantida de antemão, podendo recair em práticas de sujeição. Pode-se dizer, assim, que a construção do conhecimento e da mudança só se dá a partir da (re)construção dos próprios agentes envolvidos nesta construção, isto é, tanto pesquisadores(as) quanto pesquisados(as). Busca-se então, conforme Saffioti (1991), alternativas epistemológicas que reflitam "a permanente interação entre a maneira pela qual as pessoas entendem o mundo e quem elas são enquanto pessoas historicamente situadas" ( $p$. 150). Desta maneira, um esforço metodológico para a produção de conhecimentos que possam se constituir como alternativa para a ciência falocêntrica deve se caracterizar, entre outras coisas, por um desafio constante à objetividade, concebida como separada da subjetividade e a negação do caráter não científico da experiência.

Trata-se, portanto, de uma prática que tem como foco privilegiado as narrativas das mulheres sobre si mesmas, num processo de produção de sentidos de caráter coletivo e interativo. Conforme Spink (2004), "a produção de sentidos não é uma atividade cognitiva intra-individual, nem pura e simples reprodução de modelos predeterminados. Ela é uma prática social, dialógica, que implica a linguagem em uso" ( $p$. 42). Assinalamos, por fim, que esta estratégia metodológica se justifica pela possibilidade que carrega de reconstrução de discursos e práticas que historicamente foram desqualificadas e invisibilizadas pela lógica hegemônica androcêntrica presente nos pressupostos e nas práticas científicas.

\section{Conclusão}

Neste artigo nos perguntamos como o campo intelectual feminista pode contribuir para a emergência de um espaço de politização da intimidade de mulheres usuárias de drogas. A partir da perspectiva aqui tratada e do acompanhamento da experiência de um grupo de mulheres em tratamento em CAPS$\mathrm{AD}$, apresentamos a possibilidade de constituição desse espaço através da coletivização da experiência, do compartilhamento de saberes, da criação de redes de solidariedade e de vínculos de reciprocidade. $\mathrm{O}$ que esta experiência tem demonstrado, ainda que de forma incipiente, é que, para além do tratamento do uso abusivo de drogas, o trabalho no grupo de mulheres tem se mostrado potente ao provocar o questionamento da sua condição de gênero, por meio da interpelação coletiva sobre as relações de subordinação e opressão às quais estão submetidas e do reconhecimento dos lugares de fragilidade e insuficiência historicamente a elas atribuídos.

O foco da nossa discussão encontra-se então no reconhecimento da possibilidade de emergência do político através de ações de indivíduos e grupos, a partir da 
potencialização de processos de formação de identidade política e do reconhecimento de relações de antagonismos produtores, entre outras coisas, de usos disfuncionais de drogas em mulheres. Este argumento será mais bem elaborado em trabalhos futuros, nos quais procuraremos demonstrar de forma mais aprofundada a relação entre sexismo e uso abusivo de drogas em mulheres.

Por fim, acreditamos que a partir da identificação e superação da dicotomia entre sujeito e política torna-se possível a emergência de sujeitos autônomos. É desse modo que a análise das relações de poder, possibilitada pelas experiências de politização da intimidade, podem engendrar em mulheres usuárias de drogas engajamento e debate político, produtores de uma perspectiva crítica e atenta às intencionalidades que subjazem às práticas e discursos sociais.

\section{Referências}

Acselrad, G. (2000). A educação para a autonomia: a construção de um discurso democrático sobre o uso de drogas. In G. Acselrad (Org.), Avessos do prazer: drogas, aids e direitos humanos. Rio de Janeiro: Ed. Fiocruz.

Barros, R.B. (2007). Grupo: a afirmação de um simulacro. Porto Alegre: Sulina Editora da UFRGS.

Berlinck, M.T., Magtaz, A.C., \& Teixeira, M. (2008). A reforma psiquiátrica brasileira: perspectivas e problemas. Revista Latinoamericana de Psicopatologia Fundamental, 11(1), 21-28.

Brasil. (1996). Diretrizes para projetos de redução de danos. Brasília: Ministério da Saúde. Secretaria de Projetos Especiais de Saúde. Coordenação Nacional de Doenças Sexualmente Transmissíveis.

Brasil. (2005). Reforma psiquiátrica e politica de saúde mental no Brasil. Conferência regional de reforma dos serviços de saúde mental: 15 anos depois de Caracas. Brasília: Ministério da Saúde. Secretaria de Atenção à Saúde. Coordenação Geral de Saúde Mental. Recuperado de http://portal. saude.gov.br/portal/arquivos/pdf/relatorio_15_anos_caracas.pdf

Butler, J. (2003). Problemas de gênero: feminismo e subversão da identidade. Rio de Janeiro: Civilização Brasileira.

Carlini, B. (1999). Apresentação à edição brasileira. In G. A. Marlatt (Org.), Redução de danos: estratégias práticas para lidar com comportamentos de alto risco. Porto Alegre: Artes Médicas Sul.

Carlini, E.A., Galduróz, J.C., Noto, A.R., \& Nappo, S.A. (2002). I Levantamento domiciliar sobre o uso de drogas psicotrópicas no Brasil: estudo envolvendo as 107 maiores cidades do país. São Paulo: UNIFESP/CEBRID.

De Leon, G. (2003). A comunidade terapêutica: teoria, modelo e método. São Paulo: Loyola.
Fraser, N. (2009). Women, welfare and the politics of need interpretation. Hypatia, 2(1), 103-121.

Galduróz, J. C., Noto, A. R., \& Carlini, E.A. (1997). IV Levantamento sobre o uso de drogas entre estudantes de $1^{\circ}$ e $2^{\circ}$ graus em 10 capitais brasileiras. São Paulo: UNIFESP/CEBRID.

Grosz, E. (2000). Corpos reconfigurados. Cadernos Pagu, 14, 45-86.

Henderson D.J., Boyd C.J., \& Mieczkowski T. (1994). Gender, relationships, and crack cocaine: a content analysis. Research Nurse Health, 17, 265-272.

Hochgraf, P.B. (2001). Mulheres farmacodependentes. Jornal Brasileiro de Dependências Químicas, São Paulo, 2(1), 34-37.

Hochgraf, P.B., Zilberman, M.L., \& Brasiliano, S. (1999). A cocaína e as mulheres. In M. C. Leite \& A. Andrade (Orgs.), Cocaina e crack: dos fundamentos ao tratamento. Porto Alegre, Artmed.

Izquierdo, M.J. (1998). El malestar en la desigualdad. Madrid: Ediciones Cátedra, S.A.

Machado, L.Z. (1994). Campo intelectual e feminismo: alteridade e subjetividade nos estudos de gênero. Série Antropologia, 170. Brasília: Departamento de Antropologia da UNB.

Marlatt, G.A. (1999). Redução de danos no mundo: uma breve história. In G. A. Marlatt (Org.), Redução de danos: estratégias práticas para lidar com comportamentos de alto risco. Porto Alegre: Artes Médicas Sul.

Mata, C.C. (2008). O trabalho na comunidade terapêutica: fonte de recuperação do dependente químico. Belo Horizonte: Terra da Sobriedade.

Melucci, A. (1999). Esfera publica y democracia en la era de la información. Revista Metapolítica, 3(9), 57-67.

Melucci, A. (2001). A invenção do presente: movimentos sociais nas sociedades complexas. Petrópolis: Vozes.

Mouffe, C. (1993). O regresso do político. Lisboa: Gradiva.

Oliveira, J.F., Paiva, M.S., \& Valente, C.L.M. (2006). Representações sociais de profissionais de saúde sobre o consumo de drogas: um olhar numa perspectiva de gênero. Ciência \& Saúde Coletiva, 11(2), 473-481.

Prado, M.A.M., \& Machado, F.V. (2008). Preconceito contra homossexualidades: a hierarquia da invisibilidade. São Paulo: Cortez.

Reale. D. (1997). O caminho da redução de danos associados ao uso de drogas: do estigma à solidariedade. (Dissertação de Mestrado). Universidade de São Paulo, São Paulo.

Sabino, N., \& Cazenave, S. (2005). Comunidades terapêuticas como forma de tratamento para a dependência de substâncias psicoativas. Estudos de Psicologia, 22(2), 167-174.

Saffioti, H. (1991). Novas perspectivas metodológicas de investigação das relações de gênero. In M. A. M. Silva (Org.), Mulher em 6 tempos. Araraquara: UNESP.

Sarti, C.A. (2004). O feminismo brasileiro desde os anos 1970: revisitando uma trajetória. Revista Estudos Feministas, 12(2), 167-174.

1. United Nations Office on Drugs and Crime. World drug report [serial on the internet]. 2005 Jan [cited 2005 Apr 30];

(1): [about 10 p.]. Available from: http: //www.unodc.org/unodc/world_drug_report. Html

Marco Aurélio Máximo Prado,doutor em Psicologia Social pela Pontifícia Universidade de São Paulo, é professor Associado I na Universidade Federal de Minas Gerais. Endereço para correspondência: Rua Coletor Celso Werneck, 154/508, Santo Antônio, Belo Horizonte-MG. CEP: 31350-010. Telefone: (31)3409-6287. E-mail: mamprado@gmail.com

Isabela Saraiva de Queiroz, mestre em Psicologia Social pela Universidade Federal de Minas Gerais, é professora Assistente IV na Pontifícia Universidade Católica de Minas Gerais. E-mail: isabelasq@gmail.com 